\title{
Active gate driver for dv/dt control and active voltage clamping in an IGBT stack
}

\section{Rasmussen, Tonny Wederberg}

Published in:

European Conference on Power Electronics and Applications, 2005

Link to article, DOI:

10.1109/EPE.2005.219308

Publication date:

2005

Document Version

Publisher's PDF, also known as Version of record

Link back to DTU Orbit

Citation (APA):

Rasmussen, T. W. (2005). Active gate driver for dv/dt control and active voltage clamping in an IGBT stack. In European Conference on Power Electronics and Applications, 2005 (First ed.). IEEE.

https://doi.org/10.1109/EPE.2005.219308

\section{General rights}

Copyright and moral rights for the publications made accessible in the public portal are retained by the authors and/or other copyright owners and it is a condition of accessing publications that users recognise and abide by the legal requirements associated with these rights.

- Users may download and print one copy of any publication from the public portal for the purpose of private study or research.

- You may not further distribute the material or use it for any profit-making activity or commercial gain

- You may freely distribute the URL identifying the publication in the public portal

If you believe that this document breaches copyright please contact us providing details, and we will remove access to the work immediately and investigate your claim. 


\title{
Active gate driver for $\mathrm{dv} / \mathrm{dt}$ control and active voltage clamping in an IGBT stack
}

\author{
Tonny Wederberg Rasmussen \\ TECHNICAL UNIVERSITY OF DENMARK \\ Oersted-DTU, Automation, Elektrovej, building 325 \\ DK-2800 Kgs. Lyngby, Denmark \\ Tel: +4545253526 \\ Fax: +4545668111 \\ E-mail: twr@oersted.dtu.dk \\ URL: www.oersted.dtu.dk
}

\section{Acknowledgements}

Thanks to Jose Luis Ovelleiro Medina and Morten Juul Andersen who supplied useful input to the project. Also thanks to SEMIKRON for making it possible to obtain IGBTs in a small number.

\section{Keywords}

«Converter circuit», «Converter control», «IGBT», «Regulation», «Voltage Source Converten»

\begin{abstract}
For high voltages converters stacks of IGBTs can be used if the static and dynamic voltage sharing among the IGBTs can be applied. $\mathrm{dV}_{\mathrm{CE}} / \mathrm{dt}$ should also be controlled in order not to damage insulation material. This paper describes theory and measurements of an active gate driver for stacking IGBTs. For the measurements two series connected standard IGBTs made for hard switching applications are used. Problems are shown and proposals for improvements are given.

\section{Introduction}

When using IGBTs in converters the blocking capability is limited to about $6 \mathrm{kV}$. For high power converters in the utility systems such as ASVC (Advanced Static Var Compensators), UPFC (Unified Power Flow Control) and HVDC (High Voltage Direct Current transmission) a higher blocking voltage is necessary. The high voltage blocking capability is needed in order to avoid transformers and to transmit high power without a very high current. Instead of a single IGBT a stack (series connection) can be used [1]. To do this a good control of the static voltage across the Collector-Emitter terminals of the IGBT (Insulated Gate Bipolar Transistor) $\mathrm{U}_{\mathrm{CE}}$ and the dynamic voltage $\mathrm{du}_{\mathrm{C} C} / \mathrm{dt}$ must be carried out. For this control passive balancing [2] or an active system [3] can be used. For this use an analogue active gate driver has been constructed with an internal reference generation of the voltage $\mathrm{U}_{\mathrm{CL}}$ across the single IGBT. The functionality of the gate driver is described together with the use of active voltage clamp. Also delay problems are described and solutions are shown. Finally, the gate driver is tested in the laboratory in a stack of two IGBTs and the results for turn-on and turn-off of the IGBTs are shown together with the active clamping. The goal of this work is to control a stack of standard IGBTs.
\end{abstract}

\section{The requirement for an IGBT stack}

The laboratory setup with the IGBT stack, the load R-L and freewheeling diode $\mathrm{D}_{\mathrm{F}}$ is shown in Fig. 1. The gate driver is described in Fig. 2. 


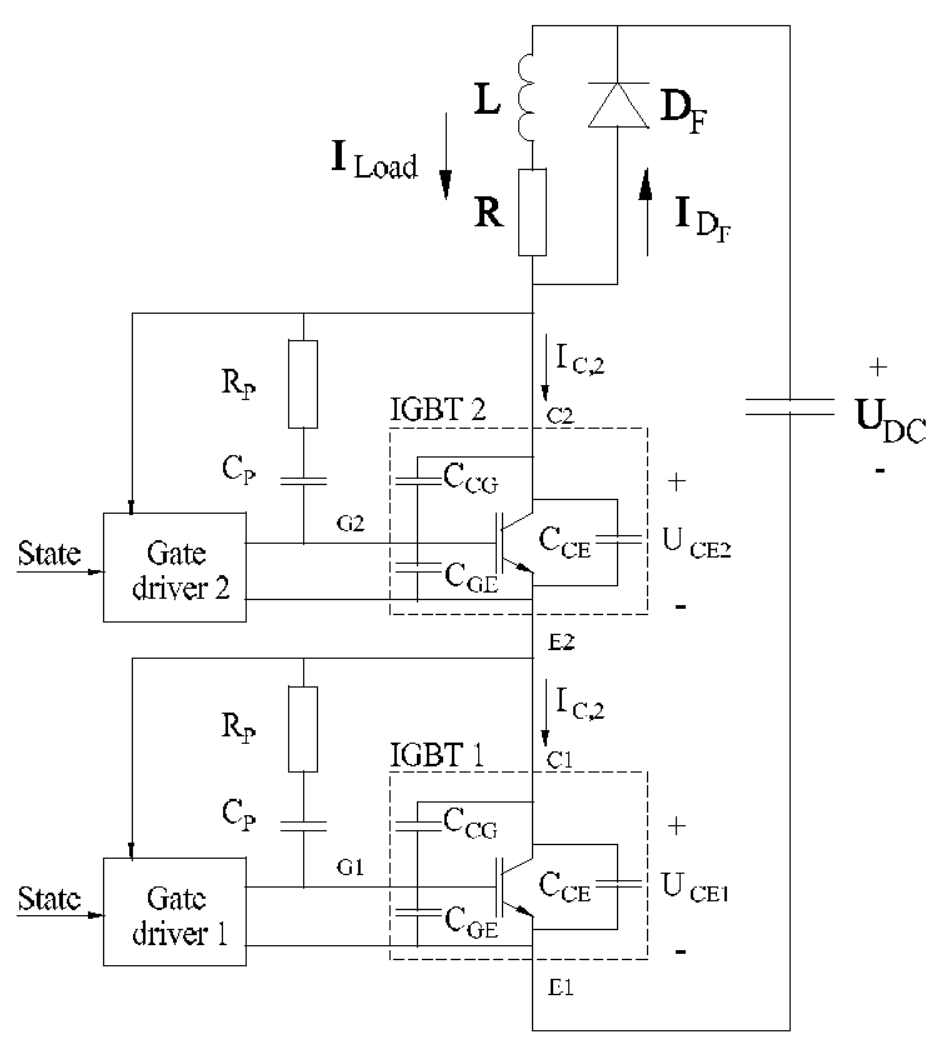

Fig. 1: The laboratory setup $U_{D C}=400 V I_{L O A D}=30 \mathrm{~A}$

When switching between on and off the single IGBTs is in the active area of operation characterized by a voltage $U_{\mathrm{GE}}$ controlled current generator $\mathrm{I}_{\mathrm{C}}(2)$. It is also surrounded by three capacitors internal in the semiconductor $\mathrm{C}_{\mathrm{Cl}}, \mathrm{C}_{\mathrm{GL}}$ and $\mathrm{C}_{\mathrm{CG}}$ where $\mathrm{C}_{\mathrm{CG}}$ changes its value depending on the voltage $\mathrm{U}_{\mathrm{CG}}$. At the test bench a capacitor $C_{P}=10 \mathrm{nF}$ in series with a damping resistor $R_{P}=18 \Omega$ is placed in parallel with the Collector-Gate terminals in order to avoid oscillations when $U_{\mathrm{GE}}=\mathrm{U}_{\mathrm{CG}}$. $\mathrm{R}_{\mathrm{P}}$ is a damping resistor. This capacitor $\mathrm{C}_{P}$ contributes to the switching loss and should be reduced in future work.

In the stationary turn on (The IGBT conduct current) there is no problem with voltage sharing while the gate voltage $\mathrm{U}_{\mathrm{GE}}$ is given as high voltage as possible and only the saturation voltage $\mathrm{U}_{\mathrm{CE} \text {,sat }}$ is seen across the IGBTs.

In the stationary turn off (The IGBT does not conduct load current) the possibility of different cut-off currents $\mathrm{I}_{\mathrm{CLS}}$ in the two IGBTs have to be taken into account while these currents can charge or recharge the capacitors $\mathrm{C}_{\mathrm{C}}$ and $\mathrm{C}_{\mathrm{CG}}$ and hereby the IGBTs do not share the voltage equally after some time. In this situation the gate driver works as an active voltage clamp circuit. When $U_{\mathrm{CE}}$ reaches the maximum value the gate driver keeps the $U_{C E}$ at that level.

The dynamic turn on process is a commutation of the load current from the free whiling diode to the IGBT and then a discharging of the capacitors (1) $\mathrm{C}_{\mathrm{CL}}$ and $\mathrm{C}_{\mathrm{CG}}$ done by the internal current generator.

$I_{C, C E}=C \frac{d u_{C E}}{d t}$ 
First, the IGBT takes over the load current from the free wheeling diode $\mathrm{I}_{D F}$ and the current $\mathrm{I}_{\mathrm{C} C \mathrm{CE}}$ that is needed to have the right $\mathrm{du}_{\mathrm{CE}} / \mathrm{dt}$ across the IGBT.

The dynamic turn off is a charging of the capacitors $C_{C \perp}$ and $C_{C G}$ with the right current (1). The IGBT turns off some of the load current and the rest of the current charges the capacitors. This means that there is lower limit of the load current and the $\mathrm{du}_{\mathrm{CE}} / \mathrm{dt}$ according to (1).

\section{The functionality of the gate driver}

The block diagram of the gate driver is seen in Fig. 2.

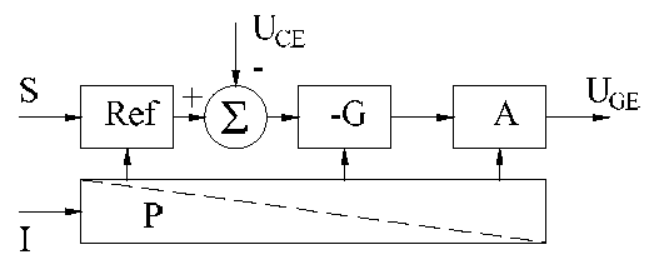

Fig. 2: The block diagram of the gate driver

$P$ is a galvanic insulated (Current transformer) power supply for the gate driver supplied by an AC current I [4]. S is a state signal for on off the IGBT supplied by a fiber-optic cable. Ref is the voltage reference generator described below. $\mathrm{G}$ is a proportional gain and $\mathrm{A}$ is an analog power amplifier for setting the voltage across $\mathrm{C}_{\mathrm{GE}}$ and hereby controls the current in the IGBT by (2) and then the voltage slope by (1).

$I_{C}=\left(U_{G E}-U_{T H}\right) \cdot G_{F S}$

The basic reference voltage is seen in Fig. 3.

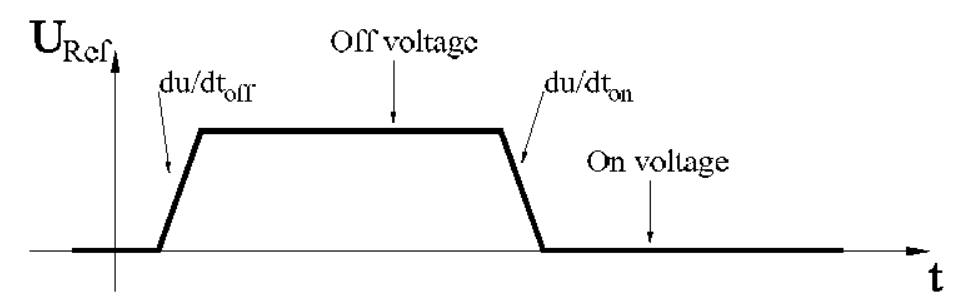

Fig. 3: Reference voltage

The du/dt $t_{\text {off }}$ is a trade-off between small losses and load current together with the bandwidth of the control system. The reference off voltage should be a little higher than the expected maximum voltage $U_{C E}$ of the IGBT in order to ensure a negative gate voltage $U_{G E}$ at the IGBT. The reference off voltage must not be too high because it has to act as an active clamp voltage for a long turn off period if the leakages currents in the IGBTs are different. Also at the turn on period a high Gate Emitter $\mathrm{U}_{\mathrm{GE}}$ should be used in order to have a low saturation voltage $U_{\mathrm{CE}}$ across the IGBT. This can be done if the reference is made negative in this period. These changes together with the state signal $\mathrm{S}$ is shown in Fig. 4 with the thin line as the reference and the tick line as the $\mathrm{U}_{\mathrm{ce}}$. 


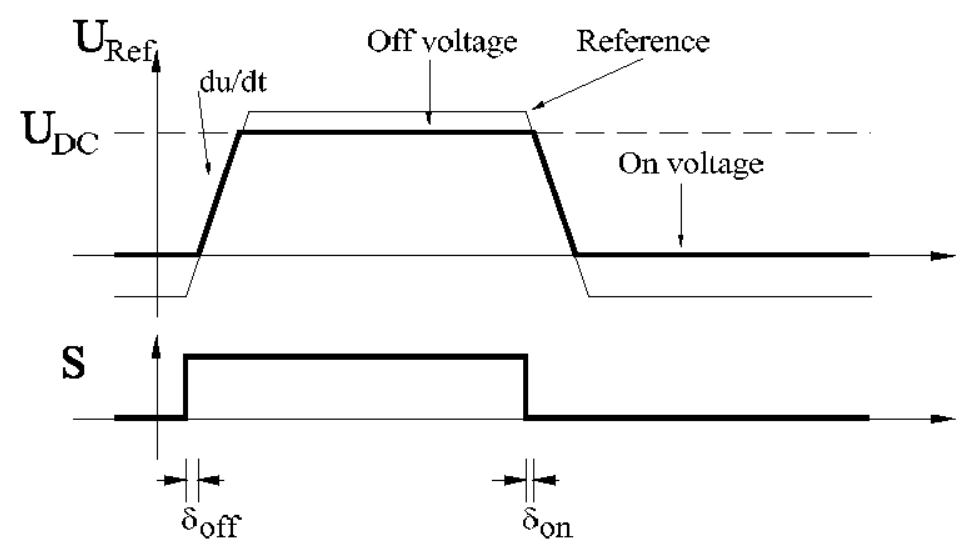

Fig. 4: State signal $S$ together with the delays and reference signal.

Some delays are seen in the system. When the state signal changes to the off it take some time $\delta_{\text {off }}$ for the reference to reach a negative value close to 0 where (after passing $G$ and A Fig. 2) the gate voltage is in the active area for the IGBT. Also at the turn on there is a small time delay $\delta_{\text {on }}$ before the IGBT reaches the active area. This delay includes commutation of the load current from the diode $\mathrm{D}_{\mathrm{F}}$ to the IGBT.

\section{Delay problem at turn on and turn off}

A solution to the delay problem is shown in Fig. 5.

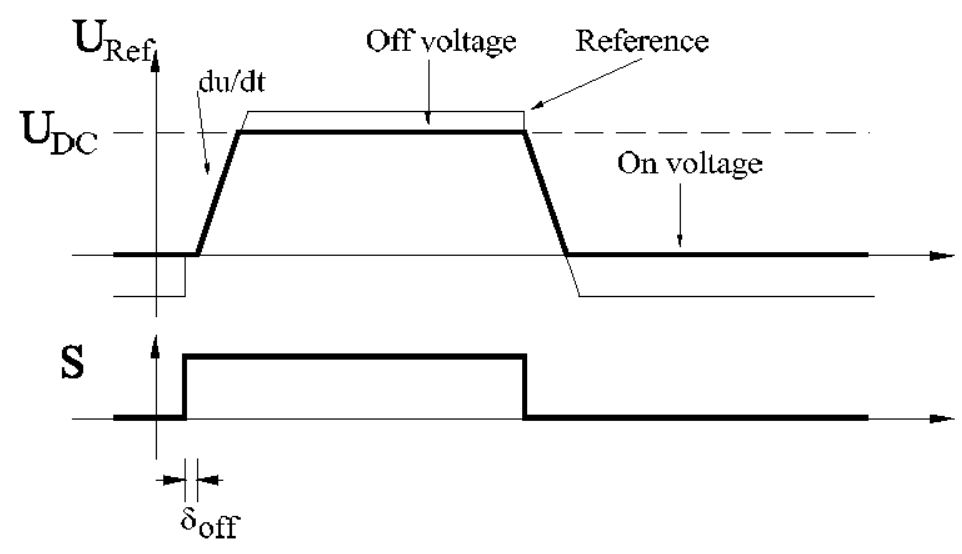

Fig. 5: Reference signal with reduction of delay

At turn off the reference signal is given a step to a negative value close to zero. Then only a small delay is needed to change the gate voltage. Also a step in the turn on could be given but is not used here while the delay is small. A step at turn on can disturb the control system if the active clamp facility is in use.

\section{Laboratory measurements of non-symmetrical conditions}

To show the function of the active clamp in the case of non-symmetry in the IGBTs' leakage currents a resistor is placed parallel with $\mathrm{C}_{\mathrm{CE}}$ across IGBT2 in Fig. 1 in order to discharge the capacitors. The resistor is used while the two leakage currents match each other very well. 


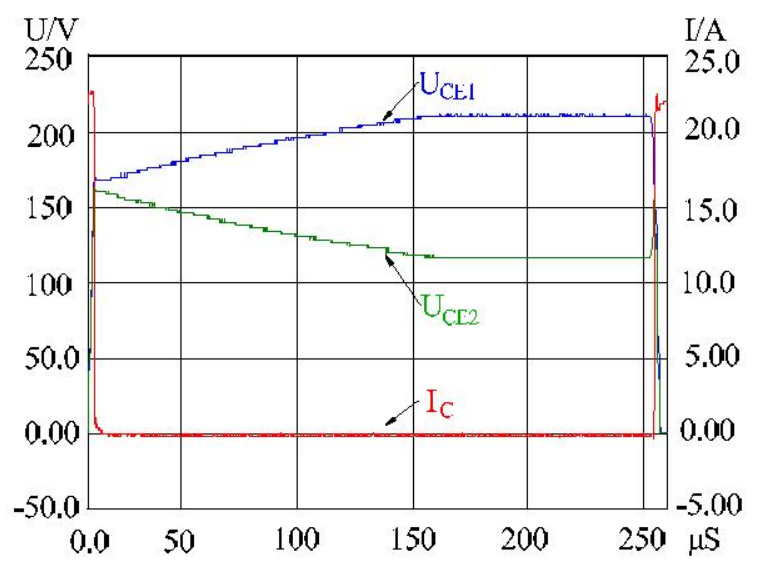

Fig. 6: Active clamping with non-symmetrical conditions

When the IGBTs are switched off $\mathrm{U}_{C E}$ increases $\mathrm{I}_{C}$ decreases to 0A and the two IGBTs share the voltage between them $\mathrm{t}=5 \mu \mathrm{s}$. The difference in leakage current caused by the resistor makes the voltage across IGBT2 decrease (Green curve $\mathrm{U}_{\mathrm{CE1}}$ ) but due to the constant DC voltage across the stack of IGBTs the voltage across IGBT1 increases. When $\mathrm{U}_{\mathrm{CL} 1}$ increases to above the reference off voltage the IGBT $_{1}$ turns on with a small collector current $I_{C}$ to keep the $U_{c e}$ constant. This is seen in Fig. 6 to $150 \mu \mathrm{S}$.

\section{Measurements of turn off at non-symmetrical conditions}

Fig. 7 shows the reaction of the control system when $U_{C E}$ passes the reference off voltage green curve $U_{R}$.
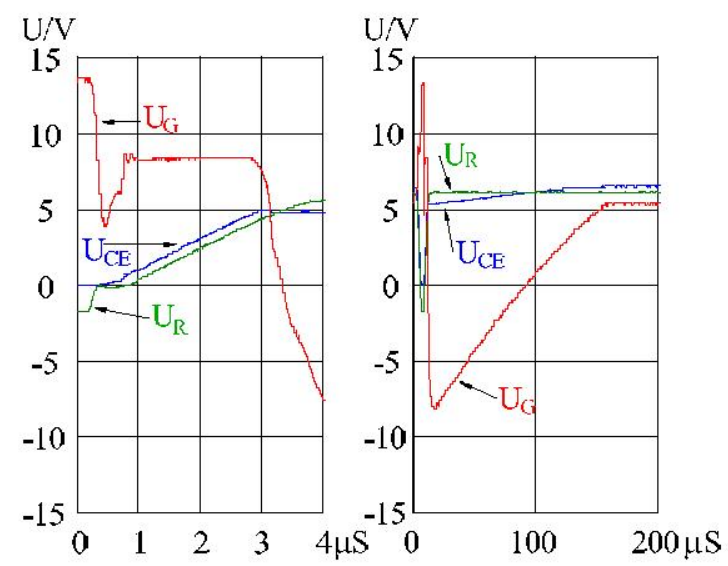

Fig. 7: Control signals at turn off. $U_{\mathrm{G}}=\mathrm{Gate}$ voltage, $\mathrm{U}_{\mathrm{R}}=$ Reference voltage, $\mathrm{U}_{\mathrm{GL}}=$ Collector Emitter voltage

On the left of Fig. 7 the gate voltage reduces when the step in reference is made to $0.5 \mu \mathrm{S}$ and after this the gate voltage drive the IGBT in the active mode to control the $\mathrm{du}_{\mathrm{C} \mathrm{C}} / \mathrm{dt}$. When the maximum DC voltage applies across the IGBTs the reference passes the $\mathrm{U}_{\mathrm{CE}}$ and the IGBT is turned completely off by the negative gate signal voltage.

In the non-symmetrical case Fig. 7 right the Collector Emitter voltage $U_{\mathrm{CE}}$ passes the reference to $100 \mu \mathrm{S}$ and the gate turns on the IGBT so $\mathrm{I}_{C}$ matches the leakage current in the other IGBT and hereby the active clamp is in function. 


\section{Measurements of turn on at non-symmetrical conditions}

When the reference decreases $U_{C L 1}$ follows the reference but IGBT2 is off while the voltage is below the reference and $\mathrm{U}_{\mathrm{CE} 2}$ increases until they share the voltage at the reference level and can then turn on $\mathrm{I}_{\mathrm{C}}$. Subsequently, the two voltages decrease until they reach the saturated on voltage.

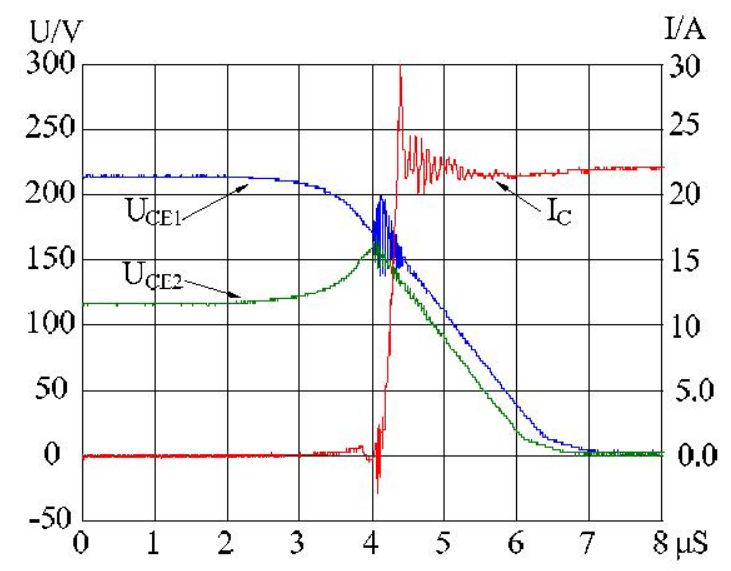

Fig. 8: Turn on after non-symmetrical voltage sharing

There is some high frequency voltage oscillation showing that it is a low inductive construction. The peak in the current comes from the reverse current in the diode.

\section{Dynamic switching at symmetrical condition}

Switch on of the IGBTs is seen in Fig. 9 under symmetrical condition where the leakage currents are equal in the two IGBTs.

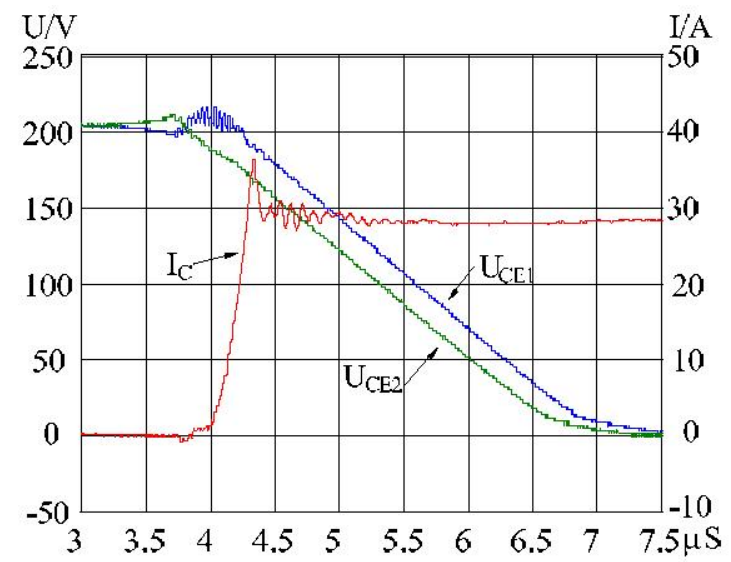

Fig. 9: Turn on of the IGBTs

To $3.5 \mu \mathrm{S}$ the reference not shown in the figure starts decreasing. As long as the collector current $\mathrm{I}_{\mathrm{C}}$ is less than the load current the total voltage $\mathrm{U}_{\mathrm{CE} 1}+\mathrm{U}_{\mathrm{CE} 2}$ across the IGBTs has to be constant while the freewheeling diode $\mathrm{D}_{\mathrm{F}}$ conducts load current see Fig. 1. In the interval $4.0 \mu \mathrm{S}$ to $4.3 \mu \mathrm{S}$ the voltage is less than 2 times $200 \mathrm{~V}$ because of the parasitic inductance from the DC power supply and between the IGBTs (bonding wires) and the free whiling diode gives a voltage drop because of high $\mathrm{dI}_{\mathrm{C}} / \mathrm{dt}$ in the current. 
The difference in gain and delay in the two control systems gives the difference between $U_{C E 1}$ and $U_{C E 2}$ at 4.0 $\mu \mathrm{S}$. For a better track of the slope a D control is needed together with an improvement in the references.

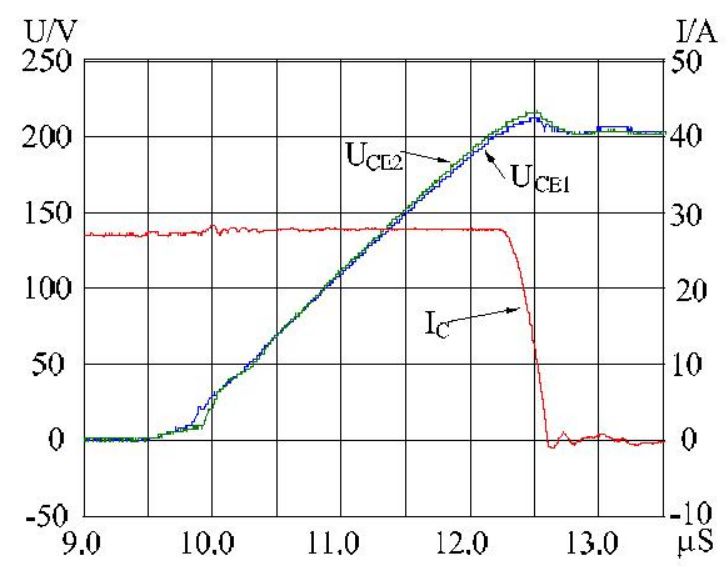

Fig. 10: Turn off of the IGBTs

At turn off the two voltages match each other well. The voltage that overshoots around $12.5 \mu \mathrm{S}$ comes from the dynamic voltage drop across the freewhiling diode when it starts to conduct current.

\section{Discussion}

To have equal conditions for the two IGBTs it is very important that the two reference signals are very similar even when they are generated separately for each IGBT.

At turn on the gain in the two control units should match each other in order to have a smaller difference between the $\mathrm{U}_{\mathrm{CE}}$ at the two IGBTs. This has been tried out but gives difficulties in the turn off process.

The switch loss for this case $U_{C E, M A X}=800, V_{C}=50 A, f_{s}=15 \mathrm{kHz}, t_{o n}+t_{o f f}=5 \mu$ s is with the used IGBT SKM 100 GB 123D from SEMIKRON is

$$
P_{S W}=f_{s W} \cdot\left(t_{o n}+t_{o f f}\right) \cdot \frac{U_{C E} \cdot I_{C}}{2}=1.5 \mathrm{~kW}
$$

This shows that the frequency $f_{\mathrm{SW}}$ and switching time $t_{\text {on }}+t_{\text {off }}$ should be reduced. If a better turn-on voltage sharing is made the switching time could be reduced. A high slope of $U_{C E}$ needs a high bandwidth of the gate driver.

The results from an ongoing detailed study of the IGBT and improvement of the reference together with a detailed circuit schematic are the subject for a future paper.

\section{Conclusion}

A gate driver for active voltage control including an active voltage clamp for stacking standard IGBTs is described. Laboratory test of an experimental setup has shown good results and pointed out where to improve the gate driver system. It has been shown that standard IGBT can be used even though they are made for hard switching application. The results of the switching are shown and discussed. 


\section{References}

[1]. Patric R. Palmer and Anthony N. Githiari. The Series Connection of IGBT's with Active Voltage Sharing. IEEE Transactions on Power Electronics, Vol. 12, No. 4 July 1997, p.237-644.

[2]. G.Busatto, B.Cascone, L.Fratelli, A.Luciano. Series Connection of IGBTs in Hard-Switching Applications Conference Record - IAS Annual Meeting (IEEE Industry Applications Society). 1998, p.825-830.

[3]. Alfio Consoli, Salvatore Musumeci, Giovanna Oriti, Antonio Testa. Active Voltage Balancement of Series Connected IGBTs. Industry Applications Conference 1995, Vol. 3, p.2752-2758.

[4]. M. A. E. Andersen, MOS Gate Driver Circuit with Extremely High Galvanic Isolation, EPE 1995, Sevilla, 1995 